\title{
FAKTOR RISIKO GANGGUAN FUNGSI PARU PADA PEKERJA BENGKEL PENGECATAN MOBIL DI KOTA PALU
}

\author{
Fellysca Veronica Margareth Politon, Christine \\ Poltekkes Kemenkes Palu \\ (fpoliton@yahoo.co.id, 085290545373)
}

Risk Factors of Pulmonary Functions Disorder on Workers Car Painting Center in Palu City

\begin{abstract}
ABSTRAK
Penelitian ini bertujuan untuk menguji faktor risiko karakteristik pekerja, pekerjaan dan kadar total partikel terhisap gangguan fungsi paru pada pekerja pengecatan mobil. Jenis penelitian ini adalah observasional dengan rancangan cross sectional. Populasi adalah pekerja pengecatan mobil di kota Palu. Sample sebanyak 96 orang dengan pengambilan sampel menggunakan simple random sampling. Peneliti menggunakan kuesioner untuk mengumpulkan data status merokok, jumlah rokok per hari, masa kerja, jumlah jam kerja dan pemakaian masker. Penliti juga menggunakan spirometer untuk mengukur variabel fungsi paru dengan tipe Datospir Mod 120B. Hasil penelitian menunjukkan adanya hubungan antara pemakaian masker dengan fungsi paru $(\mathrm{p}$-value $=0,021)$ dengan kekuatan hubungan yang lemah (koefisien Phi $\phi=0,23$ ); adanya hubungan antara masa kerja dengan fungsi paru (pvalue $=0,015$ ) dengan kekuatan hubungan yang lemah (koefisien Phi $\phi=0,28$ ) dan rasio prevalensi $3,33(95 \% \mathrm{CI}=1,33-8,36)$; sedangkan faktor kebiasaan merokok, jumlah jam kerja dan penggunaan masker tidak berhubungan dengan fungsi paru. Dengan demikian, dapat disimpulkan bahwa penggunaan masker dan masa kerja merupakan faktor risiko gangguan paru. Sehingga pekerja disarankan menggunakan masker dan mengatur jam kerja untuk mencegah risiko gangguan paru.
\end{abstract}

Kata kunci : Gangguan fungsi paru, masker, jam kerja

\section{ABSTRACT}

This reserach aims to examine whether the characteristics of workers, the job and the total levels of inhaled particles are risk factors for pulmonary function disorders on car painting workers. The type of this research was observational research with a cross sectional design. The population were car painting workers in Palu. The sample were 96 workers selected using simple random sampling. The researcher used a questionnaire to collect smoking status data, number of cigarettes a day, working period, total of working hours and the use of masks. The researcher also uses a spirometer to measure pulmonary function variables with the Mod Mode of Dat 120B. The results showed a relationship between the use of masks and pulmonary function $(p$-value $=0.021)$ is weak relationship (Phi coefficient $\phi=0.23$ ); the relationship between working period and pulmonary function ( $p$-value $=0.015)$ is weak relationship (Phi coefficient $\phi=0.28)$ the prevalence ratio 3.33 (95\% CI = 1.33-8.36); while the factors of smoking habits, total of working hours and the use of masks are not significantly related to pulmonary function. Thus, it can be concluded that the use of masks and working period are risk factors for pulmonary disorders. So that workers are advised to use masks and regulate working hours to prevent the risk of pulmonary disorders.

Keywords : Pulmonary function disorders, masks, working hours 


\section{PENDAHULUAN}

International Labour Organization (ILO) menyimpulkan setiap hari rata-rata 6.000 orang meninggal, setara dengan satu orang setiap 15 detik, atau 2,2 juta orang per tahun akibat sakit atau kecelakaan yang berkaitan dengan pekerjaan. Jumlah pria yang meninggal dua kali lebih banyak daripada wanita, karena mereka melakukan pekerjaan yang lebih berbahaya. Secara keseluruhan kecelakaan dan kesakitan di tempat kerja telah menewaskan 350.000 orang $^{(1)}$. Laju pertumbuhan angkatan kerja yang cukup besar, yaitu jumlah pekerja seluruh Indonesia per Februari 2017 adalah 97,583,141 pekerja. Jumlah pekerja yang cukup besar tersebut apabila kesehatan dan keselamatan kerjanya tidak mendapat perhatian, maka pada gilirannya dapat menyebabkan turunnya produktivitas dan daya saing pekerja. Selain itu dapat menimbulkan beban ekonomi yang sangat besar jika terjadi penyakit terkait kerja ${ }^{(2)}$.

Meskipun dampak negatif dari timbulnya penyakit terkait kerja telah diketahui, namun data tentang penyakit terkait kerja di Indonesia sampai saat ini belum terekam dengan baik. Salah satu bidang pekerjaan yang perlu mendapat perhatian adalah penyakit akibat kerja pada pekerja pengecatan mobil. Salah satu penyakit terkait kerja pada pekerja pengecatan mobil tersebut adalah gangguan fungsi paru. Partikel terinhalasi yang merupakan penyebab langsung dari gangguan fungsi paru ditentukan oleh beberapa variabel yaitu ukuran partikel, intensitas (kadar) dan durasi dari paparan, serta daya tahan pekerja. Partikel dengan ukuran diameter $5 \mu$ atau lebih kecil dapat mencapai alveoli. Selain ukuran yang sangat kecil, intensitas dan durasi paparan yang lama akan menyebabkan partikel terdeposit dalam alveoli sehingga dalam jangka panjang terjadi penurunan fungsi paru.

Partikel kontaminan hasil dari aktivitas pengecatan bersifat toksik dan merupakan bahan karsinogenik. Apabila masuk ke dalam saluan pernafasan dapat mengakibatkan terjadinya fibrosis yang selanjutnya dapat menurunkan kapasitas vital paru dan dalam jangka panjang dapat menyebabkan kanker. Selain itu dalam cat terdapat juga bahan kimia isocyanate dan pelarut toluene yang terbukti dapat menurunkan kapasitas vital paru. Maka pekerja akan mempunyai risiko untuk terjadinya gangguan fungsi paru ${ }^{(3)}$.

\section{METODE PENELITIAN}

Penelitian ini merupakan penelitian observasional dengan menggunakan rancangan cross sectional. Lokasi penelitian beberapa bengkel mobil di Kota Palu pada bulan Juli tahun 2017. Populasi dan sampel adalah pekerja pengecatan mobil di Kota Palu yang bersedia untuk dijadikan objek penelitian. Pengambilan sampel dengan simple random sampling. Alat dan Bahan dalam penelitian adalah Kuesioner sebagai instrumen untuk mengumpulkan data status merokok, jumlah rokok per hari, masa kerja, jumlah jam kerja dan pemakaian masker. Dengan Spirometer untuk mengukur variabel fungsi paru dengan tipe DATOSPIR Mod 120B. 


\section{HASIL}

Gambar 1 menunjukkan bahwa lebih banyak pekerja bengkel pengecatan mobil yang tidak mengalami gangguan paru, yaitu 80 responden $(83,3 \%)$ dibandingkan dengan pekerja yang menderita gangguan paru yaitu 16 responden (16,6\%). Gambar 2 menunjukkan bahwa lebih banyak pekerja bengkel pengecatan mobil yang tidak memakai masker saat bekerja yaitu 76 responden ( 79\%) dibandingkan dengan pekerja yang memakai masker yaitu 20 responden (21\%). Gambar 3 menunjukkan pekerja bengkel pengecatan mobil yang mempunyai masa kerja <10 tahun $(66,6 \%)$ lebih banyak dibandingkan dengan $\geq 10$ tahun, yaitu 32 responden (33,3\%). Dari gambar 4 dapat dilihat bahwa lebih banyak pekerja bengkel pengecatan mobil yang mempunyai jam kerja per minggu $>40$ jam sebanyak 94 responden $(97,91 \%)$ dibandingkan dengan $<40$ jam yaitu 2 responden (2,08\%). Dari gambar 5 dapat dilihat bahwa lebih banyak pekerja bengkel pengecatan mobil yang mempunyai kebiasaan merokok sebanyak 68 responden $(71 \%)$ dibandingkan dengan yang tidak merokok yaitu 28 responden (29\%). Dari gambar 6 dapat dilihat bahwa lebih banyak pekerja bengkel pengecatan mobil yang mempunyai kebiasaan konsumsi rokok per hari >10 batang sebanyak 61 responden $(63,54 \%)$ dibandingkan dengan yang $<10$ batang per hari yaitu 35 responden $(36,45 \%)$.

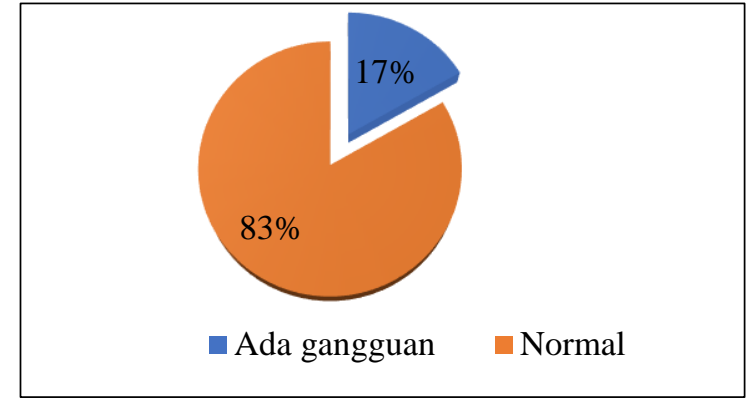

Gambar 1. Distribusi pekerja bengkel pengecatan mobil berdasarkan gangguan fungsi paru di Kota Palu

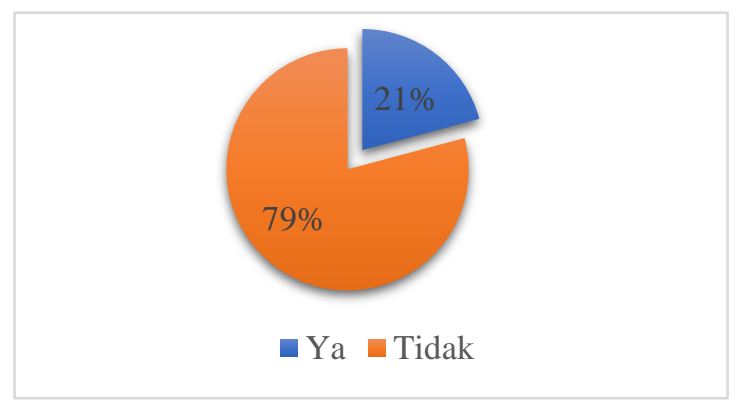

Gambar 2. Distribusi Pekerja Bengkel Pengecatan Mobil berdasarkan Pemakaian Masker di Kota Palu Tahun 2017

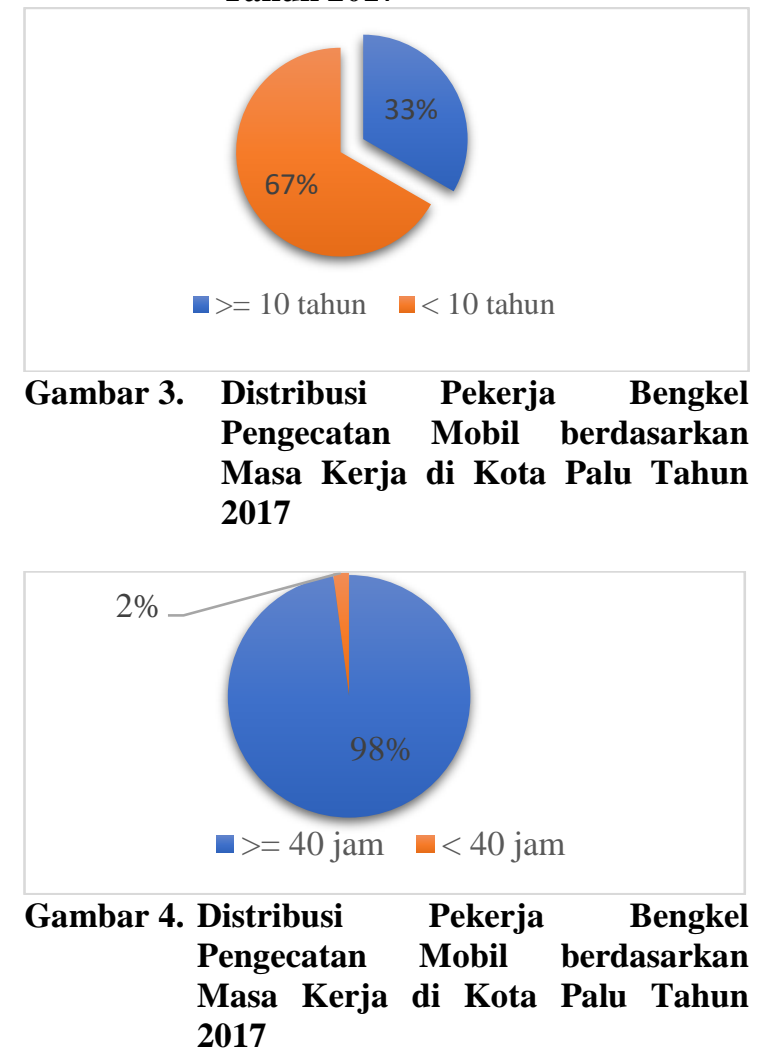



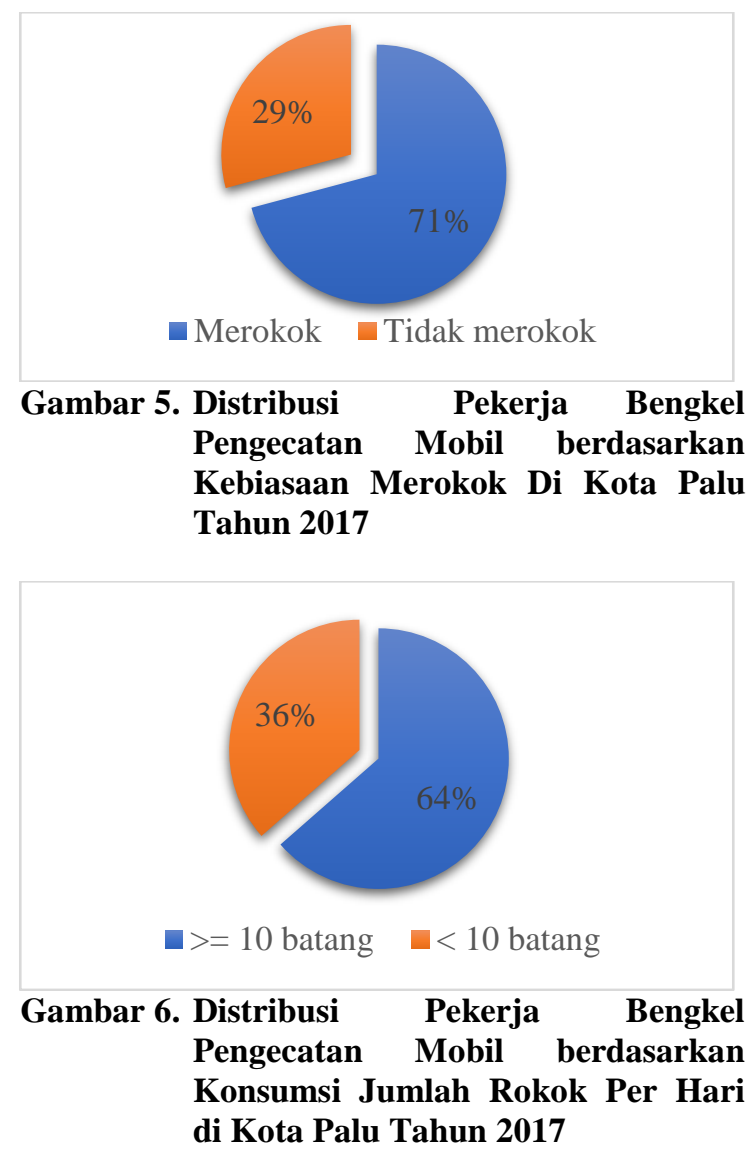

Tabel 1. Hubungan Faktor Risiko dengan Fungsi Paru Pekerja Bengkel Pengecatan Mobil di Kota Palu

\begin{tabular}{|c|c|c|c|c|}
\hline \multirow[b]{2}{*}{ Variabel } & \multicolumn{2}{|c|}{ Fungsi paru } & \multirow[b]{2}{*}{ Total } & \multirow[b]{2}{*}{ p-value } \\
\hline & $\begin{array}{c}\text { Ada } \\
\text { Gangguan }\end{array}$ & Normal & & \\
\hline \multicolumn{5}{|l|}{$\begin{array}{l}\text { Pemakaian } \\
\text { masker }\end{array}$} \\
\hline Tidak & $16(21,1 \%)$ & $60(78,9 \%)$ & 76 & 0,021 \\
\hline $\mathrm{Ya}$ & $0(0,0 \%)$ & $20(100,0 \%)$ & 20 & \\
\hline \multicolumn{5}{|l|}{ Masa Kerja } \\
\hline$\geq 10$ tahun & $10(31,3 \%)$ & $22(68,8 \%)$ & 32 & 0,015 \\
\hline$<10$ tahun & $6(9,4 \%)$ & $58(90,6 \%)$ & 64 & \\
\hline \multicolumn{5}{|l|}{ Jumlah Jam } \\
\hline $\begin{array}{l}\geq 40 \mathrm{jam} \\
<40 \mathrm{jam}\end{array}$ & $\begin{array}{c}15(16,0 \%) \\
1(50,0 \%)\end{array}$ & $\begin{array}{c}79(84,0 \%) \\
1(50,0 \%)\end{array}$ & $\begin{array}{c}94 \\
2\end{array}$ & 0,307 \\
\hline \multicolumn{5}{|l|}{ Kebiasaan } \\
\hline $\begin{array}{l}\text { Merokok } \\
\text { Tidak Merokok }\end{array}$ & $\begin{array}{c}13(19,1 \%) \\
3(10,7 \%)\end{array}$ & $\begin{array}{l}55(80,9 \%) \\
25(89,3 \%)\end{array}$ & $\begin{array}{l}68 \\
28\end{array}$ & 0,382 \\
\hline Jumlah & & & & \\
\hline $\begin{array}{l}\text { Rokok } \\
\geq 10 \text { batang } \\
<10 \text { batang }\end{array}$ & $\begin{array}{c}12(19,7 \%) \\
4(11,4 \%)\end{array}$ & $\begin{array}{l}49(80,3 \%) \\
31(88,6 \%)\end{array}$ & $\begin{array}{l}61 \\
35\end{array}$ & 0,448 \\
\hline
\end{tabular}

Sumber: Data Primer, 2017

\section{PEMBAHASAN}

\section{Massa Kerja}

Hasil analisis uji univariat dan bivariat menunjukkan bahwa pekerja bengkel dengan masa kerja diatas 10 tahun mempunyai peluang risiko untuk menderita gangguan paru sebanyak 3,33 kali lebih besar dibandingkan dengan pekerja bengkel yang masa kerja dibawah 10 tahun dengan hasil $\mathrm{p}$ value 0,015 dan CI 95\% 1,33-8,36.

Hasil penelitian ini sejalan dengan hasil penelitian Budiono yang menyatakan bahwa pekerja bengkel pengecetan mobil dengan masa kerja 10 tahun mempunyai peluang risiko hampir 15 kali lebih besar untuk mengalami gangguan paru ${ }^{(4)}$.

\section{Pemakaian Masker}

Hasil analisis uji bivariat menunjukkan bahwa ada hubungan antara pemakain masker dengan gangguan paru dengan nilai $\mathrm{p}$ value 0,015 , hasil sejalan dengan hasil penelitian Budiono yang menyatakan bahwa pekerja bengkel pengecetan mobil yang tidak memakai masker saat bekerja beresiko untuk mengalami gangguan paru hampir 15 kali lebih besar dibandingkan dengan pekerja yang selalu menggunakan masker, paparan debu saat bekerja tinggi dapat diminalisir dengan penggunaan masker, selain itu dengan mekanisme pertahanan berupa refleks muntah, maka partikel debu yang lolos dari masker akan dicegah agar tidak masuk kedalam trachea. 


\section{Jumlah Jam Kerja}

Dari hasil uji bivariat pada variabel jumlah jama kerja per minggu didapatkan hasil tidak ada hubungan antara gangguan paru dengan jumlah jam kerja dengan $\mathrm{p}$ value $=$ 0,307 , hasil penelitian ini tidak sesuai dengan teori yang menyatakan bahwa semakin lama pekerja terpapar oleh paparan debu akan semakin besar risiko terjadinya gangguan paru, hal ini bisa disebabkan kondisi kerja di lapangan berbeda tingkat dan intensitas paparan dari masing-masing pekerja dan juga bisa dilihat dari aspek lain seperti fungsi paruparu yang masih sehat, serta daya ketahanan tubuh dari masing-masing orang yang berbeda serta aspek lain seperti status gizi dan kebiasaan olahraga dan pola hidup pekerja yang berbeda satu sama lain.

\section{Kebiasaan Merokok}

Pada variabel ini hasil analisis bivariat didapatkan bahwa tidak ada hubungan kebiasaan merokok dengan gangguan fungsi paru pada pekerja bengkel pengecetan mobil, hasil penelitian oleh Gold dalam irwan yang menyatakan bahwa kebiasaan merokok pada pekerja yang terpapar oleh debu memperbesar kemungkinan untuk terjadinya gangguan fungsi paru, dalam penelitian ini didapatkan hasil yang berbeda bisa disebabkan oleh lamanya waktu mulai merokok dan umur responden.

\section{Jumlah Rokok Per hari}

Pada variabel ini analisa bivariat didapatkan bahwa tidak ada hubungan jumlah konsumsi rokok per hari dengan gangguan fungsi paru pada pekerja bengkel pengecetan mobil, hal ini tidak sesuai dengan hasil penelitian oleh Gold dalam irwan yang menyatakan bahwa kebiasaan merokok pada pekerja yang terpapar oelh debu memperbesar kemungkinan untuk terjadinya gangguan fungsi paru, dalam penelitian ini didapatkan hasil yang berbeda bisa disebabkan oleh lamanya waktu mulai merokok dan umur responden.

\section{KESIMPULAN DAN SARAN}

Hasil penelitian menunjukkan adanya hubungan antara pemakaian masker dengan fungsi paru; adanya hubungan antara masa kerja dengan fungsi paru; sedangkan faktor kebiasaan merokok, jumlah jam kerja dan penggunaan masker tidak berhubungan dengan fungsi paru. Dengan demikian, dapat disimpulkan bahwa penggunaan masker dan masa kerja merupakan faktor risiko gangguan paru. Sehingga pekerja disarankan menggunakan masker dan mengatur jam kerja untuk mencegah risiko gangguan paru.

\section{DAFTAR PUSTAKA}

1. Jurnal Kesmas, USSU, 2004

2. BPS, 2017

3. Wahyuningsih dkk, 2003

4. Budiono, Irwan, (2007) Faktor Risiko Gangguan Fungsi Paru Pada Pekerja Pengecatan Mobil, Tesis Program Pasca Sarjana Universias Diponegoro Semarang.

5. Guyton, Arthur, (2007) Fisiologi Kedokteran, Alih bahasa Ken Ariata Tengadi Edisi 11, EGC, Jakarta.

6. Giafina, fihir (2013), Analisis Gangguan Fungsi Paru pada Pekerja di Bengkel Body Repair X, Universitas Indonesia, Jakarta

7. Laksmi, Wulandari, (2010) Hubungan Antara Inhalasi Cat Semprot dengan Faal Paru Pekerja Pengecatan Mobil, Fakulas Kedokteran Universitas Airlangga Surabaya. 
8. Kawatu, Paul, Modul Kebijakan Kesehatan Kerja, Pasca Sarjana Program Studi Ilmu Kesehatan Masyarakat Universitas Samratulangi Manado.

9. Khumaidah,(2009) Analisis Faktor-faktor yang Berhubungan Dengan Gangguan Fungsi Paru pada Pekerja Mebel PT. Kota Jati Kabupaten Jepara, Tesis, Semarang Universitas Diponegoro

10. Riswati, Y., (2004) Hubungan masa kerja dengan kapasitas vital paksa paru pada pekerja pengecatan mobil di kampung Ligu Kota Semarang, Skripsi. Fakultas Kesehatan Masyarakat Universitas Diponegoro Semarang.

11. Riduwan, (2006) Belajar Mudah Penelitian, Alfabeta, Jakarta.

12. Suma'mur, PK., (2009) Higiene Perusahaan dan Kesehatan Kerja, Sagung Seto, Jakarta.

13. Suyatno, (2006) Menghitung Besar Sampel Penelitian Kesehatan Masyarakat, Materi Kuliah Fakulas Kesehatan Masyarakat, Universias Diponegoro Semarang.

14. Wahyuningsih, Faisal Y., Mukhtar I., (2003) Dampak Inhalasi Cat Semprot Terhadap Kesehatan Paru, Cermin Kedokteran.

15. WHO. (1995) Deteksi Dini Penyakit Akibat Kerja, EGC, Jakarta.

16. Ismail, (2011) Kebijakan Keselamatan dan Kesehatan Kerja, www.healthsafetyprotection.com.

17. Tinjauan Umum Terhadap Keselamaan Kesehatan Kerja (K3) dan Sisem Manajemen K3, Jurnal Kesehatan Masyarakat, Universitas Sumatera Utara, 2004 